\title{
Inheritance and fitness effects of a pericentric inversion and a supernumerary chromosome segment in Muscari comosum (Liliaceae)
}

\author{
M. A. GARRIDO-RAMOS*†, M. J AMILENAt, R. DE LA HERRÁN $\dagger$, C. RUIZ REJ ÓN†, \\ J.P. M. CAMACHO† \& M. RUIZ REJ ONं \\ †Departamento de Genética, Facultad de Ciencia, Universidad de Granada, 18071 Granada, Spain and \\ łDepartamento de Biología Aplicada, Escuela Superior de Ingenieros Agrónomos, Universidad de Almería, Almería, \\ Spain
}

\begin{abstract}
The inheritance and the effects on fitness of a pericentric inversion and a supernumerary chromosome segment (SCS) involving the second chromosome pair of Muscari comosum, have been analysed in an experimental population. Whereas the inversion is inherited in a Mendelian fashion through the female side, the SCS shows a powerful accumulation mechanism $(k=0.796)$. Cases of nonrandom pollination were observed in homozygous bulbs for the standard chromosomes $(++)$ and also in those homozygous for the inverted chromosomes (ii), which may be caused by a certain rate of self-pollination. The different karyotypes for both the inversion and the SCS showed similar values for several life-history traits related to female fitness, such as bulb weight, number of fruits, number of seeds and seed weight. However, plants carrying the inversion had heavier bulbs than those lacking it. The significance of these observations is discussed in relation to the maintenance of the two types of polymorphism in natural populations.
\end{abstract}

Keywords: accumulation mechanism, fitness effects, inheritance pattern, Muscari comosum, pericentric inversion, supernumerary segment.

\section{Introduction}

Although pericentric inversion polymorphism has frequently been reported in natural populations of animals, particularly in rodent and grasshopper species (White, 1973), it has rarely been found in plants, with the exception of a few cases in maize (Morgan, 1950) and some Liliaceae such as Allium thunbergii (Watanabe \& Noda, 1974) or Muscari comosum (Bentzer \& Ellmer, 1975). One of the most widespread cases of polymorphism for pericentric inversion reported in plants was found in $M$. comosum L. (Liliaceae) $(2 n=18)$, where all natural populations analysed from the Mediterranean region (from Greece to the Canary Islands) showed this polymorphism in the second longest chromosome pair (Bentzer \& Ellmer, 1975; Ruiz Rejón \& Oliver, 1981; Ruiz Rejón et al., 1990). In addition, this same chromosome pair shows a polymorphism for an

*Correspondence. E-mail: mgarrido@ugr.es euchromatic supernumerary chromosome segment (SCS) (Ruiz Rejón et al., 1987), a kind of polymorphism especially frequent in natural populations of grasshoppers (Hewitt, 1979; Camacho et al., 1984) and plants (Rhoades, 1942; Ruiz Rejón \& Ruiz Rejón, 1985; Jamilena et al., 1991, 1995).

The pericentric inversion reaches quite high frequencies in natural populations of Muscari comosum $\left(q_{\mathrm{i}}=0.34\right.$ on average $)$, and there are only slight between-population frequency differences over the geographical distribution of the polymorphism, although the inverted chromosomes tend to be less frequent in populations located at ecological borders (Ruiz Rejón et al., 1990). The SCS is also present over the whole geographical range, but at a much lower frequency, and thus some populations lack it (Ruiz Rejón et al., 1990).

It is of interest to identify the factors that determine the maintenance of these polymorphisms in natural populations. The analysis of the association of these polymorphisms with certain enzymatic loci, 
and the calculation of the $F_{\mathrm{I}}, F_{\mathrm{IS}}, F_{\mathrm{ST}}$ and $F_{\mathrm{IT}}$ $F$-statistics (Wright, 1951), provided indirect evidence that both types of polymorphism could be maintained by means of natural selection (Ruiz Rejón et al., 1990). Although M. comosum is a bulbous member of the family Liliaceae, its reproduction is entirely sexual. This has been borne in mind while preparing the present paper where we directly analyse the two most important factors determining the maintenance of any polymorphism: inheritance and fitness effects. There are few reports of pericentric inversion inheritance in natural populations (Viseras \& Camacho, 1991), but SCSs have been profusely studied and appear to show a frequent tendency to non-Mendelian transmission (Rhoades, 1942; Wilby \& Parker, 1988; López-León et al., 1992). Here we analyse the inheritance and fitness effects of both types of polymorphism in $M$. comosum, grown in an experimental plot simulating field conditions.

\section{Materials and methods}

The present work was carried out in an experimental population of 71 bulbs of Muscari comosum that were randomly planted in an experimental plot in the autumn of 1994. Karyotypes for the pericentric inversion and the SCS were previously known: 38 $(+/+), 18(+/ \mathrm{i}), 11(\mathrm{i} / \mathrm{i})$, two $(+/+1)$, one $(+/ \mathrm{il})$ and one $(\mathrm{i} / \mathrm{il})$, where + indicates the standard submetacentric chromosome, $\mathrm{i}$ indicates the acrocentric chromosome produced by pericentric inversion, and +1 or il indicate the presence of a SCS in the long arm of chromosomes + or $\mathrm{i}$, respectively (for details, see figs 1-4 in Ruiz Rejón \& Oliver, 1981 and fig. 2 in Ruiz Rejón et al., 1987).

The bulbs, originally collected in Lluvi (Mallorca, Spain), were planted at random in a plot of $7 \times 4 \mathrm{~m}$. The plot was located far from natural populations of the species so that it would constitute a closed population where panmixis is possible. In the spring of 1995, the plants were allowed to reproduce naturally and their offspring were collected individually. For each plant, bulb weight, number of fruit, number of seeds and seed weight were recorded. In the autumn of 1995, all seeds obtained from each of 28 bulbs were sown to calculate germination ratio. For transmission studies, the karyotype of seeds from 17 bulbs was analysed by squashing roots in $2 \%$ acetic orcein.

Transmission analysis for each polymorphism was performed as follows. In homozygous bulbs, the null hypothesis $\left(\mathrm{H}_{0}\right)$ was that they produced heterozygous seeds at a frequency predicted by random fertilization with pollen from the 71 bulbs present in the experimental population. In heterozygous bulbs, however, inheritance was analysed by means of three statistical tests similar to those proposed by Perfectti \& Pascual (1996) for controlled crosses. The first test $\left(\chi_{\mathrm{g}}^{2}\right)$ reveals whether the two chromosomes appear in the seeds at the frequencies predicted by Mendelian segregation in the heterozygous bulbs following random pollination from the 71 bulbs $\left(\mathrm{H}_{0}\right)$. When the $\mathrm{H}_{0}$ is rejected, this test may indicate the existence of meiotic drive on the female side, pollen selection and/or zygotic selection in seeds. The second test $\left(\chi_{z}^{2}\right)$ includes the same assumptions as the first, but analyses karyotypic frequencies in the seed progeny, $\mathrm{H}_{0}$ being that these frequencies are consistent with those expected under female Mendelian segregation and random pollen usage. When significant, this test suggests the existence of zygotic selection, assortative mating or assortative fertilization. The third test $\left(\chi_{\mathrm{h}}^{2}\right)$ analyses whether half of the offspring are heterozygotes $\left(\mathrm{H}_{0}\right)$, and generically provides information on whether segregation is Mendelian in at least one sex. For the present data, however, this test indicated specifically whether transmission was Mendelian through the female side of heterozygous bulbs. That is, we did not analyse controlled crosses, but rather motheroffspring where male parents were unknown and could be multiple, so that the $\mathrm{H}_{0}$ has to assume a random sample of pollen from all 71 bulbs present in the experimental population. Thus, except if the expected pollen frequency were close to $1: 1,50 \%$ of heterozygous seeds can be yielded only through Mendelian segregation on the female side. For the two types of polymorphism analysed, the expected pollen frequencies were rather far from 1:1 (0.697/0.303 for $+/ \mathrm{i}$ chromosomes in the inversion and $0.972 / 0.028$ for $+/ 1$ chromosomes in the SCS). Thus, in the present analysis, 50\% heterozygous seeds are expected from Mendelian segregation on the female side. The possibility still remains that a $50 \%$ frequency of heterozygous seeds might be derived from female transmission bias compensating frequency differences in the random pollen sample. For instance, a $0.4+/ 0.6 \mathrm{i}$ sample of egg cells (resulting from inversion drive) fertilized by a random pollen sample $(0.7+/ 0.3 \mathrm{i})$ would yield offspring with a slight excess of heterozygotes (0.54). But this excess is directly dependent on the magnitude of drive for the i chromosome (e.g. 0.62 for drive equal to 0.8 ). This indicates that the most parsimonious hypothesis is to assume that $50 \%$ heterozygotes is not likely from Mendelian segregation through the female, because the corresponding test will only be 
weak for low drive values. In the case of the SCS, where pollen frequencies were much more biased from 0.5 (see above), the possibility of a compensating effect is even more unrealistic.

For the statistical analysis of effects on life-history traits, our first step was to investigate whether each variable was normally distributed, by means of the Shapiro-Wilk's test. Because only bulb weight fitted a normal distribution, nonparametric tests were applied in all cases. All statistical tests were carried out using BMPD statistical software (Dixon, 1990).

\section{Results}

Inheritance analyses

Table 1 shows very high heterogeneity in pollen fertilization success between homozygous bulbs, with an average excess of ++ seedlings when the bulbs were ++ and ii seeds when they were ii. The analysis of heterozygous bulbs (Table 2) showed that these bulbs yielded about half heterozygous seeds, implying that the + and i chromosomes were transmitted at the Mendelian ratio on the female side $\left(\chi_{\mathrm{h}}^{2}\right.$

Table 1 Inheritance analysis of a pericentric inversion in Muscari comosum in homozygous bulbs. The null hypothesis was that they received a random sample of pollen from the whole population, so that each homozygote is expected to produce a frequency of heterozygous seeds equal to the population frequency of the chromosome it does not carry

\begin{tabular}{|c|c|c|c|c|c|c|c|c|c|}
\hline \multirow[b]{2}{*}{ Karyotype } & \multirow[b]{2}{*}{$\begin{array}{c}\text { Bulb } \\
\text { no. }\end{array}$} & \multicolumn{3}{|c|}{ Observed seeds } & \multicolumn{3}{|c|}{ Expected seeds } & \multirow[b]{2}{*}{$\chi_{1}^{2}$} & \multirow[b]{2}{*}{$P$} \\
\hline & & Homozygous & Heterozygous & $\begin{array}{l}\text { Proportion of } \\
\text { heterozygotes }\end{array}$ & Homozygous & Heterozygous & $\begin{array}{l}\text { Proportion of } \\
\text { heterozygotes }\end{array}$ & & \\
\hline \multirow[t]{8}{*}{++} & 3 & 8 & 9 & 0.529 & 11.85 & 5.15 & 0.303 & 4.13 & 0.042 \\
\hline & 8 & 78 & 9 & 0.103 & 60.64 & 26.36 & 0.303 & 16.40 & $<0.001$ \\
\hline & 15 & 47 & 6 & 0.113 & 36.94 & 16.06 & 0.303 & 9.04 & 0.003 \\
\hline & 17 & 41 & 33 & 0.446 & 51.58 & 22.42 & 0.303 & 7.16 & 0.007 \\
\hline & 25 & 83 & 20 & 0.194 & 71.79 & 31.21 & 0.303 & 5.78 & 0.016 \\
\hline & 47 & 33 & 21 & 0.389 & 37.64 & 16.36 & 0.303 & 1.89 & 0.169 \\
\hline & 64 & 24 & 9 & 0.273 & 23.00 & 10.00 & 0.303 & 0.14 & 0.708 \\
\hline & Total & 314 & 107 & 0.254 & 293.44 & 127.56 & 0.303 & 44.54 & $<0.001$ \\
\hline \multicolumn{10}{|c|}{$\chi_{\text {heterog. }}^{2}=39.79$, d.f. $=6, P<0.001 ; \chi_{\text {accumul. }}^{2}=4.75$, d.f. $=1, P=0.029$} \\
\hline ii & 13 & 13 & 36 & 0.735 & 14.85 & 34.15 & 0.697 & 0.33 & 0.566 \\
\hline & 22 & 42 & 27 & 0.391 & 20.91 & 48.09 & 0.697 & 30.52 & $<0.001$ \\
\hline & 23 & 18 & 26 & 0.591 & 13.33 & 30.67 & 0.697 & 2.35 & 0.125 \\
\hline & 29 & 13 & 29 & 0.690 & 12.73 & 29.27 & 0.697 & 0.01 & 0.920 \\
\hline & 33 & 3 & 14 & 0.824 & 5.15 & 11.85 & 0.697 & 1.29 & 0.256 \\
\hline & Total & 89 & 132 & 0.597 & 66.96 & 154.04 & 0.697 & 34.50 & $<0.001$ \\
\hline \multicolumn{10}{|c|}{$\chi_{\text {heterog. }}^{2}=24.09$, d.f. $=4, P<0.001 ; \chi_{\text {accumul. }}^{2}=10.41$, d.f. $=1, P=0.001$} \\
\hline
\end{tabular}

Table 2 Inheritance analysis of a pericentric inversion in Muscari comosum in heterozygous bulbs $(+\mathrm{i})$

\begin{tabular}{|c|c|c|c|c|c|c|c|c|c|c|c|c|}
\hline \multirow[b]{2}{*}{ Bulb no. } & \multicolumn{3}{|c|}{ Observed } & \multicolumn{3}{|c|}{$\chi_{\mathrm{g}}^{2}$} & \multicolumn{3}{|c|}{$\chi_{z}^{2}$} & \multicolumn{3}{|c|}{$\chi_{\mathrm{h}}^{2}$} \\
\hline & ++ & $+\mathrm{i}$ & ii & $\chi^{2}$ & $P$ & $P^{\prime}$ & $\chi^{2}$ & $P$ & $P^{\prime}$ & $\chi^{2}$ & $P$ & $P^{\prime}$ \\
\hline 5 & 16 & 26 & 10 & 0.74 & 0.390 & NS & 0.82 & 0.664 & NS & 0.00 & 1.000 & NS \\
\hline 6 & 14 & 24 & 7 & 0.17 & 0.680 & NS & 0.28 & 0.867 & NS & 0.20 & 0.655 & NS \\
\hline 16 & 10 & 12 & 6 & 0.18 & 0.671 & NS & 1.02 & 0.600 & NS & 0.57 & 0.450 & NS \\
\hline 30 & 13 & 30 & 20 & 12.53 & 0.0004 & 0.0016 & 15.18 & 0.0005 & 0.002 & 0.14 & 0.708 & NS \\
\hline 36 & 34 & 72 & 13 & 0.11 & 0.740 & NS & 5.38 & 0.068 & NS & 5.25 & 0.022 & NS \\
\hline
\end{tabular}

$P^{\prime}$, probability corrected by the sequential Bonferroni method. 
was nonsignificant in the five cases). Bulb no. 30, however, yielded a significant excess of ii seeds.

With respect to the SCS, Table 3 shows that bulbs carrying both chromosomes lacking the SCS, received a random sample of pollen. The heterozygous bulbs, however, produced a highly significant excess of heterozygous seeds, in most cases paralleled by a significant increase in the frequency of 1 chromosomes transmitted (Table 4).

\section{Effects on fitness}

Forty-six bulbs were used to analyse possible fitness effects of both polymorphisms: 19 bulbs were ++ , 14 bulbs were $+\mathrm{i}$, nine bulbs were ii, two bulbs were $+/+1$ (bulbs nos 47 and 64), one bulb was $+/$ il (bulb no. 30) and one bulb was i/il (bulb no. 33). Four fitness-related life-history traits were recorded: bulb weight, number of fruits, number of seeds and seed weight. Three additional variables were obtained by combination of these four: the mean number of seeds per fruit, the absolute investment of a bulb in seed production (calculated as the product of the number of seeds and the mean weight per seed) and the relative investment in seeds (calculated as the absolute investment in seeds divided by bulb weight).

Nonparametric Spearman rank correlation analyses of the variables measured showed a significant trend for large bulbs to yield larger seeds $\left(r_{\mathrm{s}}=0.532, N=46, t=4.17, P=0.00014\right)$, but no significant correlation was found between bulb size

Table 3 Analysis of pollen usage by Muscari comosum bulbs lacking a supernumerary chromosome segment (SCS). The null hypothesis was that they received a random sample of pollen from the whole population, so that each ++ bulb is expected to produce a frequency of heterozygous seeds $(+1)$ equal to the frequency of the SCS in the population $(0.028)$

\begin{tabular}{|c|c|c|c|c|c|c|c|c|}
\hline \multirow[b]{2}{*}{ Bulb no. } & \multicolumn{3}{|c|}{ Observed seeds } & \multicolumn{3}{|c|}{ Expected seeds } & \multirow[b]{2}{*}{$\chi_{1}^{2}$} & \multirow[b]{2}{*}{$P$} \\
\hline & ++ & +1 & Proportion +1 & ++ & +1 & Proportion +1 & & \\
\hline 3 & 17 & 0 & 0 & 16.52 & 0.48 & 0.028 & 0.49 & 0.484 \\
\hline 5 & 48 & 3 & 0.059 & 49.56 & 1.44 & 0.028 & 1.75 & 0.186 \\
\hline 6 & 44 & 1 & 0.022 & 43.73 & 1.27 & 0.028 & 0.06 & 0.806 \\
\hline 8 & 85 & 2 & 0.023 & 84.55 & 2.45 & 0.028 & 0.08 & 0.777 \\
\hline 13 & 47 & 2 & 0.041 & 47.62 & 1.38 & 0.028 & 0.29 & 0.590 \\
\hline 15 & 52 & 1 & 0.019 & 51.51 & 1.49 & 0.028 & 0.17 & 0.680 \\
\hline 16 & 26 & 2 & 0.071 & 27.21 & 0.79 & 0.028 & 1.91 & 0.167 \\
\hline 17 & 73 & 1 & 0.014 & 71.92 & 2.08 & 0.028 & 0.58 & 0.446 \\
\hline 22 & 68 & 1 & 0.014 & 67.06 & 1.94 & 0.028 & 0.47 & 0.493 \\
\hline 23 & 43 & 1 & 0.023 & 42.76 & 1.24 & 0.028 & 0.05 & 0.823 \\
\hline 25 & 101 & 2 & 0.019 & 100.10 & 2.90 & 0.028 & 0.29 & 0.590 \\
\hline 29 & 42 & 0 & 0 & 40.82 & 1.18 & 0.028 & 1.22 & 0.269 \\
\hline 36 & 114 & 5 & 0.042 & 115.65 & 3.35 & 0.028 & 0.83 & 0.362 \\
\hline Total & 760 & 21 & 0.027 & 759.00 & 22.00 & 0.028 & 8.19 & 0.831 \\
\hline \multicolumn{9}{|c|}{$\chi_{\text {heterog. }}^{2}=8.14$, d.f. $=12, P=0.774 ; \chi_{\text {accumul. }}^{2}=0.05$, d.f. $=1, P=0.823$} \\
\hline
\end{tabular}

Table 4 Inheritance analysis of a SCS in Muscari comosum in heterozygous bulbs

\begin{tabular}{|c|c|c|c|c|c|c|c|c|c|}
\hline \multirow[b]{2}{*}{ Bulb no. } & \multicolumn{3}{|c|}{ Observed } & \multicolumn{3}{|c|}{$\chi_{\mathrm{g}}^{2}$} & \multicolumn{3}{|c|}{$\chi_{\mathrm{h}}^{2}$} \\
\hline & ++ & +1 & 11 & $\chi^{2}$ & $P$ & $P^{\prime}$ & $\chi^{2}$ & $P$ & $P^{\prime}$ \\
\hline 30 & 17 & 46 & 1 & 6.63 & 0.010 & 0.030 & 13.35 & 0.00026 & 0.00078 \\
\hline 33 & 3 & 14 & 0 & 3.78 & 0.052 & NS & 7.12 & 0.008 & 0.016 \\
\hline 47 & 5 & 49 & 0 & 20.01 & 0.000008 & 0.000032 & 35.85 & $<0.00001$ & $<0.00004$ \\
\hline 64 & 11 & 22 & 0 & 1.64 & 0.200 & NS & 3.67 & 0.055 & NS \\
\hline
\end{tabular}

$P^{\prime}=$ Probability corrected by the sequential Bonferroni method. Because of the extremely low frequency of the 11 bulbs, the $\chi_{\mathrm{g}}^{2}$ and the $\chi_{\mathrm{z}}^{2}$ tests are practically equivalent 
and the number of fruits, number of seeds, seeds per fruit or absolute investment in seeds (data not shown). Likewise, the number of fruits did not correlate with seed weight or the number of seeds per fruit. Finally, no significant correlation was found between seed weight and the number of seeds.

Table 5 shows that the two karyotypes carrying the pericentric inversion $(+\mathrm{i}$ and ii) had a bulb weight significantly higher than ++ individuals. The remaining traits did not differ significantly between karyotypes. Values for all traits, being closely similar between the two karyotypes carrying the inversion, were pooled for subsequent analyses. MannWhitney tests confirmed that the pericentric inversion affected bulb weight $(z=3.12, P=0.0126$ after correction by the sequential Bonferroni method) but not the remaining traits. Contrast of variances showed that variance in the relative seed investment was significantly greater in bulbs carrying the inversion $\left(F_{20,24}=5.63, P=0.0007\right.$ after correction by the sequential Bonferroni method) (see SE values in Table 5), but no other trait was affected. Similar analyses showed no effect of the SCS on any of the variables shown in Table 5, at both mean and variance levels.

Finally, the three karyotypes differing for the pericentric inversion did not show significant differences in germination rate $(75.29 \%$ for,$++ 81.89 \%$ for $+\mathrm{i}$ and $82.18 \%$ for ii; Kruskal-Wallis ANOvA: $H=1.85, N=28, P=0.40)$. The SCS also had no effect on germination rate (Mann-Whitney test: $z=0.68, P=0.49$ ).

\section{Discussion}

Our results provide new insights into several aspects of the inheritance and fitness of both a pericentric inversion and a SCS located in the second chromosome pair of $M$. comosum. With respect to the inheritance of the inversion, some homozygous bulbs (either with or without inversion) showed nonrandom pollination. As is apparent in Table 1, the homozygous standard bulbs $(++)$ showing nonrandom pollination yielded an excess of homozygous standard seedlings, and the homozygous bulbs for the inversion (ii) with nonrandom pollination produced an excess of homozygous seedlings for the inversion. The most likely explanation is the existence of a certain rate of self-pollination. In this respect, it has been demonstrated by isozyme analyses that the reproductive biology of $M$. comosum tends towards cross-pollination (Ruiz Rejón et al., 1982, 1985). However, its floral characteristics do not rule out the possibility of a certain rate of self-pollination (Knoll, 1921); in this regard Bentzer (1973) found some seed-setting after spontaneous selfing in this species.

As a whole, Table 2 indicates that the majority of bulbs heterozygous for the inversion $(+\mathrm{i})$ showed Mendelian ratios on the female side and random pollination, with the exception of bulb no. 30. As this bulb was doubly heterozygous $(++/ \mathrm{il})$, the excess of ii seeds was most likely a consequence of hitch-hiking caused by the accumulation of the SCS. In fact this bulb yielded $13(++/++)$, four $(++/ \mathrm{i}+), 26(++/ \mathrm{il})$ and $20(\mathrm{i}+/ \mathrm{il})$ seeds. Therefore, it produced 46 seeds ( $73 \%$ of total progeny) carrying an il chromosome most probably inherited from the mother. The high tendency for the transmission of the il chromosome, as a whole, through the mother is explained by the fact that both the inversion and the SCS suppress chiasma formation (Ruiz-Rejón et al., 1987). The high transmission rate of the inversion in this bulb was thus a passive

Table 5 Comparison of seven fitness-related traits between the three karyotypes for the inversion, by means of the Kruskal-Wallis nonparametric ANOVA

\begin{tabular}{|c|c|c|c|c|c|c|c|c|c|}
\hline \multirow[b]{2}{*}{ Item } & \multicolumn{2}{|c|}{$++(N=21)$} & \multicolumn{2}{|c|}{$+\mathrm{i}(N=15)$} & \multicolumn{2}{|c|}{ ii $(N=10)$} & \multicolumn{3}{|c|}{ Kruskal-Wallis ANOvA } \\
\hline & Mean & SE & Mean & SE & Mean & SE & $H$ & $P$ & $P^{\prime}$ \\
\hline Bulb weight & 4.55 & 0.42 & 6.70 & 0.71 & 6.54 & 0.44 & 9.857 & 0.0072 & 0.050 \\
\hline Number of fruits & 36.29 & 4.19 & 26.00 & 3.76 & 27.10 & 4.85 & 3.135 & 0.2085 & NS \\
\hline Number of seeds & 141.00 & 19.07 & 105.33 & 19.93 & 100.90 & 23.10 & 2.707 & 0.2584 & NS \\
\hline Mean seed weight & 6.50 & 0.53 & 7.00 & 0.32 & 7.89 & 0.67 & 5.017 & 0.0814 & NS \\
\hline Seeds per fruit & 4.01 & 0.35 & 3.94 & 0.32 & 3.41 & 0.33 & 1.298 & 0.5225 & NS \\
\hline Absolute investment in seeds & 852.55 & 121.26 & 754.69 & 146.50 & 785.53 & 172.55 & 0.421 & 0.8103 & NS \\
\hline Relative investment in seeds & 231.27 & 44.33 & 122.71 & 25.24 & 114.84 & 21.49 & 6.178 & 0.0456 & NS \\
\hline
\end{tabular}

$P^{\prime}$, probability corrected by the sequential Bonferroni method. 
consequence of SCS accumulation. The absence of significance for the $\chi^{2}$-test in Table 2 for this bulb is not a consequence of a Mendelian segregation ratio through the mother (which would run against the accumulation of the il chromosome). In this case, the $50 \%$ of seeds heterozygous for the inversion is simply the result of random fertilization of two types of egg cells with frequencies biased in favour of the il type $(0.27++: 0.73$ il $)$ by two types of pollen with frequencies $(0.62++: 0.38+\mathrm{i})$, which are those expected from a random pollen sample from the 71 bulbs in the experimental population.

These results indicate that the pericentric inversion in M. comosum shows Mendelian transmission through both the paternal and maternal lines, but also suggest that linkage to the SCS (hitch-hiking) could give the inversion some transmission advantage. In other words, the il chromosome was transmitted with a higher efficiency than the +1 chromosome in double heterozygotes. This possibility remains to be tested in future work where double heterozygotes in coupling and repulsion phases can be analysed for transmission.

It is surprising that although pericentric inversion polymorphisms have been frequently reported in a wide variety of organisms (White, 1973; Watanabe $\&$ Noda, 1974), the transmission of the standard and inverted chromosomes has rarely been analysed, even though this is one of the main factors determining the maintenance of polymorphism. The only known case was reported by Viseras \& Camacho (1991) in the grasshopper Aiolopus strepens, where a gravid female collected in the field transmitted the standard and the inverted chromosome at about the same rate. Our present data point to the same result, suggesting that pericentric inversions do not seem to show drive, but more cases need to be analysed before a firm conclusion can be reached.

Analysis of seedlings from bulbs lacking the SCS showed that they received a random sample of pollen with respect to the SCS (Table 3 ). However, three out of the four bulbs heterozygous for the SCS produced a significant excess of heterozygous seedlings (Table 4). This non-Mendelian transmission most likely results from an accumulation mechanism on the female side involving preferential segregation of the 1 chromosome to the egg cell in heterozygotes. From the sum of karyotypic frequencies in the seeds of the four heterozygous bulbs $(36++$, $131+1,1 \mathrm{ll})$ and assuming random pollen fertilization (the + chromosome at a frequency of 0.972 and the 1 at a frequency of 0.028 ), we can calculate the transmission ratio of the 1 chromosome $\left(k_{1}\right)$ : frequency of heterozygotes $=0.972 \times k_{1}+0.028 \times$ $\left(1-k_{1}\right)$, so that $131 /(36+131+1)=0.972 \times k_{1}+$ $0.028-0.028 k_{1} ; \quad k_{1}=(0.78-0.028) /(0.972-0.028)=$ 0.796. The average transmission ratio for the 1 chromosome is thus about 0.8 , which implies a powerful accumulation mechanism favouring the increase in frequency of the SCS in this population.

It is common to find that SCSs display accumulation mechanisms. Examples have been reported in plants such as maize (Rhoades, 1942), Tulipa australis (Ruiz Rejón et al., 1988), Rumex acetosa (Wilby \& Parker, 1988), or at the tetraploid level of Scilla autumnalis (Ainsworth et al. 1983), and animals like the grasshopper Chorthippus jacobsi (in the $\mathrm{S}_{8}$ chromosome; López-León et al., 1992). Other SCSs, however, reveal Mendelian transmission, as in the cases of Scilla autumnalis at the diploid level (Jamilena et al., 1995) or the grasshopper Chorthippus jacobsi $\left(\mathrm{M}_{5}\right.$ and $\mathrm{M}_{6}$ chromosomes; López-León et al., 1992) and the locust Locusta migratoria (Pardo et al., 1993), and there is even a case in the grasshopper Eyprepocnemis plorans where the SCS is undertransmitted through heterozygous females carrying B chromosomes (López-León et al., 1991, 1994). Thus, SCSs constitute excellent material for investigating accumulation mechanisms.

The absence of phenotypic correlation between seed weight and seed number indicates the absence of an offspring size-to-number trade-off. This may be because the experimental population experienced more benign conditions than most natural populations. In another lily plant, Scilla autumnalis, however, we also failed to find this trade-off in a natural population (Jamilena et al., 1995). This might be a general characteristic of bulbous plants, because the bulb may provide sufficient nutrients for the plant to avoid resource limitation during reproduction.

Our results have shown that the different karyotypes for the two types of chromosomal polymorphism in the second chromosome pair of M. comosum displayed similar values for several life-history traits related to female fitness, such as number of fruits, number of seeds and seed weight. However, those plants carrying the inversion had heavier bulbs than those lacking it (Table 5), and a greater variance in the relative seed investment. In addition, plants carrying the inverted chromosome showed a significant trend towards a lower relative investment in seeds, although significance was lost after Bonferroni application (Table 5). This suggests that inversion carriers may benefit by having heavier bulbs that allocate relatively less energy to reproduction, thus reserving more resources for other functions. If variation for relative investment in seeds involves 
additive genetic variation, then natural selection could favour the pericentric inversion. Because relative seed investment was similar for $+\mathrm{i}$ and ii individuals (Table 5), and other factors being equal, this process should lead to the fixation of the inverted chromosome. Calculation of heritability and analysis of the frequency of standard and inverted chromosomes in natural populations, over several years, will clarify the details of the maintenance of this polymorphism. For the moment, we know that it is not maintained by intragenomic selection, because it does not show drive, and it may be maintained through the action of phenotypic selection, which would not be surprising given the intimate relationship between inversions and supergenes (Prakash \& Lewontin, 1968).

The SCS, however, is clearly maintained by powerful drive on the female side. This suggests its selfish nature, the same as that of other SCSs showing drive. We have not detected any effect on fitness, although this result should be considered preliminary because only four bulbs carrying the SCS could be analysed.

It is clear that SCSs can be maintained in natural populations only by showing drive or else by exerting some beneficial effect on carriers. The first applies to the case of $M$. comosum (the present study) and the second to the case of Scilla autumnalis, where transmission is Mendelian but SCS presence (mainly in heterozygotes) results in heavier seeds (Jamilena et al., 1995). There is even one species where both mechanisms seem to take place. Tulipa australis shows drive for the SCS and a higher germination rate for heterozygous seeds (Ruiz Rejón et al., 1988). The SCS in M. comosum could thus be considered a selfish element, that in $S$. autumnalis a heterotic one, and that in T. australis a strange case where a selfish element has evolved to benefit carriers.

An additional interesting question is why the SCS in $M$. comosum displays a low frequency in natural populations despite showing such high drive and not being detrimental to carrier fitness. A possible answer is a recent origin of the SCS, but this possibility is not supported by its presence in most populations analysed (Ruiz Rejón et al., 1990). In addition, the euchromatic nature of the SCS suggests, under the hypothesis by Camacho \& Cabrero (1987), that it could actually be a relic of a chromosome segment that formed part of the standard genome but underwent a tolerated deletion, and thus now is in the last stage of a process leading to its disappearance. If this is correct, then it might have gained accumulation in Mallorca, a property absent from most of the remaining populations. Testing this hypothesis would require inheritance analyses in populations where SCS frequency is low. If true, it would explain why the SCS was so frequent in two populations analysed from this island but so rare in the remaining populations. It is also remarkable that two populations collected at Menorca, a nearby island, lacked the SCS, which suggests the high importance of genetic drift, in general, and founder effects, in particular, in making up SCS frequency in natural populations.

\section{Acknow ledgements}

We wish to express our gratitude to two Erasmus students in the University of Granada, Mrs D. Altmann from Rostock (Germany) and Mr R.A.W. Lowe from Reading (UK) for technical assistance. This work was supported by a grant of Plan Andaluz de Investigación de la Junta de Andalucía (Group No. CVI 0200).

\section{References}

AINSWORTh, C. C., PARKeR, J. S. AND HORTON, D. 1983. Chromosome variation and evolution in Scilla autumnalis. In: Brandham, P.E. \& Bennett M.D. (eds) Kew Chromosome Conference II, pp. 261-268. HMSO, London.

BENTZER, B. 1973. Taxonomy, variation and evolution in representatives of Leopoldia Parl. (Liliaceae) in the southern and central Aegean. Bot. Notiser, 126, 69-132.

BENTZER, B. AND ELLMER, M. 1975. A case of stable chromosomal polymorphism in Leopoldia comosa (Liliaceae). Hereditas, 81, 127-132.

CAMACHO, J. P. M. AND CABRERO, J. 1987. New hypotheses about the origin of supernumerary chromosome segments in grasshoppers. Heredity, 58, 341-343.

CAMACHO, J. P. M., VISERAS, E., NAVAS, J. AND CABRERO, J. 1984. C- heterochromatin content of supernumerary chromosome segments in grasshoppers: detection of an euchromatic extra segment. Heredity, 53, 167-175.

DIXON, w. J. (ed.) 1990. BMDP Statistical Software Manual. University of California Press, Berkeley.

HEWITT, G. M. 1979. Grasshoppers and crickets. In: John, B. (ed.) Animal Cytogenetics, vol 3. Gebrüder-Borntraeger, Berlin, Stuttgart.

JAMILENA, M., MARTÍNEZ, F., GARRIDO-RAMOS, M. A., RUIZ REJÓN, C., ROMERO, A. T., CAMACHO, J. P. M. et al. 1995. Inheritance and fitness effects analysis for a euchromatic supernumerary chromosome segment in Scilla autumnalis (Liliaceae). Bot. J. Linn. Soc., 118, 249-259.

JAMILENA, M., RUIZ REJÓN, C. AND RUIZ REJÓN, M. 1991. Variation in the heterochromatin and NORs of Allium subvillosum L. (Liliaceae). Genome, 33, 779-784.

KNOLL, F. 1921. Insekten und Blumen. Experimentelle Arbeiten zur Vertiefung unserer Kenntnisse über die

(c) The Genetical Society of Great Britain, Heredity, 80, 724-731. 
Wechselbeziehungen zwischen Pflanzen und Tieren. Abh. Zool. Bot. Ges. Wien, 12, 1-119.

LÓPEZ-LEON, M. D., CABRERO, J. AND CAMACHO, J. P. M. 1991. Meiotic drive against an autosomal supernumerary segment promoted by the presence of a B chromosome in females of the grasshopper Eyprepocnemis plorans. Chromosoma, 100, 282-287.

LÓPEZ-LEON, M. D., CABRERO, J. AND CAMACHO, J. P. M. 1992. Male and female segregation distortion for heterochromatic supernumerary segments on the S8 chromosome of the grasshopper Chortippus jacobsi. Chromosoma, 101, 511-516.

LÓPEZ-LEON, M. D., PARDO, M. C., CABRERO, J. AND CAMACHO, J. P. M. 1994. Undertransmission of a supernumerary chromosome segment through heterozygous females possessing B chromosomes in the grasshopper Eyprepocnemis plorans. Genome, 37, 705-709.

MORGAN, D. T., JR. 1950. A cytogenetic study of inversions in Zea mays. Genetics, 35, 153-174.

PARDO, M. C., VISERAS, E., CABRERO, J. AND CAMACHO, J. P. M. 1993. A supernumerary chromosome segment in Locusta migratoria. Genome, 36, 919-923.

PeRfeCtTI, F. AND PASCUAL, L. 1996. Segregation distortion of isozyme loci in cherimoya (Annona cherimola Mill). Theor. Appl. Genet., 93, 440-446.

PRAKASH, S. AND LEWONTIN, R. C. 1968. A molecular approach to the study of genic heterozygosity in natural populations. III. Direct evidence of coadaption in gene arrangements in Drosophila. Proc. Natl. Acad. Sci., U.S.A., 59, 398-405.

RHOADES, M. M. 1942. Preferential segregation in maize. Genetics, 27, 395-407.

RUIZ REJÓN, M. AND OLIVER, J. L. 1981. Genetic variability in Muscari comosum (Liliaceae). I. A comparative analysis of chromosome polymorphism in Spanish and Aegean populations. Heredity, 47, 403-407.

RUIZ REJÓN, C. AND RUIZ REJÓN, M. 1985. Chromosomal polymorphism for a heterochromatic supernumerary segment in a natural population of Tulipa australis (Link) (Liliaceae). Can. J. Genet. Cytol., 27, 633-638.

RUIZ REJÓN, C., LOZANO, R., ORTEGA NIETO, F. J. AND RUIZ REJÓN, M. 1988. B-chromosomes and supernumerary chromosome segments of Liliaceae: selfish or heterotic DNA? In: Brandham, P. E. (ed.) Kew Chromosome Conference III, pp. 141-150. HMSO, London.

RUIZ REJÓN, C., LOZANO, R. AND RUIZ REJÓN, M. 1987. Genetic variability in Muscari comosum L. (Liliaceae). II. Characterization and effects on chiasma formation of the polymorphic variants of chromosome 2. Genome, 29, 19-26.

RUIZ REJÓN, C., LOZANO, R. AND RUIZ REJÓN, M. 1990. Genetic variability in Muscari comosum L. (Liliaceae). IV. Geographical distribution and adaptive role of the polymorphic variants of chromosome 2 . Genetica, 81 , 133-142.

RUIZ REJón, M., PASCUAL, L., RUIZ REJón, C., VALDÉS, B. AND OLIVER, J. L. 1985. A new species of Muscari subgenus Lepoldia from the Iberian Peninsula. Biochem. Syst. Ecol., 13, 239-250.

RUIZ REJón, M., PÉREZ, L., PASCUAL, L., RUIZ REJÓN, C., LÓPEZ, D. AND OLIVER, J. L. 1982. An estimate of the outcrossing rate in natural populations of Muscari comosum (Liliaceae). Preliminary note. Isozyme Bull., $\mathbf{1 5}, 106$.

VISERAS, E. AND CAMACHO, J. P. M. 1991. Effects and maintenance of a pericentric inversion polymorphism in the grasshopper Aiolopus strepens. Heredity, 66, 325-331.

WATANABE, H. AND NODA, s. 1974. Chiasma studies in structural hybrids. XI. Pericentric inversion in Allium thunbergii. Nucleus, 17, 114-117.

white, M. J. D. 1973. Animal Cytology and Evolution, 3rd edn. Cambridge University Press, Cambridge.

WILBY, A. s. AND PARKER, J. s. 1988. The supernumerary segment systems of Rumex acetosa. Heredity, 60, 109-117.

WRIGHT, s. 1951. The genetical structure of populations. Ann. Eugen., 15, 323-354. 